\title{
Effect addition of Cinnamomum cassia on treatment of pathological infections in Cyprinus carpio L. fingerlings
}

\author{
M.A. Mohammad ${ }^{1}$, Sh.K. AL-Taee ${ }^{\circledR}$ and Z.M. AL-Jumaa ${ }^{3} \mathbb{C}$ \\ ${ }^{1}$ Department of Animal Production, College of Agriculture, ${ }^{2}$ Department of Pathology and Poultry Disease, ${ }^{3}$ Department of \\ Internal and Preventive Medicine, College of Veterinary Medicine, University of Mosul, Mosul, Iraq
}

Article information

Article history:

Received September 3, 2020

Accepted January 21, 2021

Available online October 1, 2021

\section{Keywords:}

Isolation bacteria

Histopathological changes

Cinnamomum cassia

Food additive

Cyprinus carpio

Correspondence:

M.A. Mohammad

dr.mahmoud@uomosul.edu.iq

\begin{abstract}
The goal of this study was to isolate and identify the causative agents that causes death in Yankee Hatch / Erbil fingerling Cyprinus carpio and to investigate the effect of Cinnamon on the infected fish handled. Both Staphylococcus aureus and Escherichia coli are strongly isolate followed by Aeromonas hydrophila and Klebsiella pneumonia were isolated from liver, kidney and intestine which cause histopathological changes in these organs, characterized by fibrosis in liver, coagulative necrosis in renal tubules in the kidney and sever enteritis. Cinnamomum cassia added to the ration of infected fish at concentration $0.75,1$ and $1.5 \%$ for eight weeks. The histopathological examination reveals that the $1.5 \%$ is best the percentage used as food additive for repair and regenerative tissue damage in the liver, kidney and intestine. These study conclude that $C$. cassia have been used as additive food in fish feed ration at $1.5 \%$ and have important role in regenerative tissue damage and keep fish in health status.
\end{abstract}

DOI: 10.33899/ijvs.2021.128258.1564, (CAuthors, 2021, College of Veterinary Medicine, University of Mosul.

This is an open access article under the CC BY 4.0 license (http://creativecommons.org/licenses/by/4.0/).

\section{Introduction}

One of the fastest growing industries in the animal products industry is aquaculture, it is a good source of protein for human consumption as percentage $77 \%$ of fish directly and $23 \%$ indirect consumption (1). Freshwater fish Cypinidies are the important productive fish in the world and are an important protein source for human, but it susceptible to disease due to stressful condition as overcrowding of breeding, bad management, feeding, physiological status of fish and suppression of immune system. all these condition lead to loss defense mechanisms and facilitates the spread of pathogenic microorganisms which may inhabiting in the water environment and cause disease and high mortality (2,3). Antibiotic and chemotherapeutic agents are more common used in aquaculture for controlling fish diseases and may be used for long period these lead to high resistance of microorganisms, so it necessary to elevate fish defense mechanisms through administration of immune stimulus as Spirulina spp. which consider a good promotion growth and production in $C$. carpio (4) and some additive plant act as scavenger agent for removal mycotoxin (5). Other act as alternative for antibiotic in fish farming (6-9). Administration of medicinal plants is favorite method can be treat bacterial diseases as gram positive and gram negative bacteria as Staphylococcus spp., Streptococcus and Aeromonas hydrophila $(10,11)$ one of these plant is Cinnamomum cassia has biological properties as analgesic carminative, hemostatic, antiseptic, antispasmodic, insecticidal, antiparasite and antifungal (12). Cinnamon stimulate innate immunity, so it used to treat disease, inflammation gastrointestinal disorder and urinary infections $(13,14)$. The chemical composition which consist from flavonoids, saponins and tannins have antioxidant, anti-inflammatory activity and have ability to reduce effects of free radicals to keep cell physiology (15). The aims of the study are isolation and identification the causative agents that cause death in illness fish in Yankee hatch and to determine therapeutic effects of food supplementation of Cinnamomum cassia for treated illness fish. 


\section{Materials and methods}

During period January - May 2020, one hundred fifty illness fingerlings (Cyprinus carpio) (16) $15 \pm 2 \mathrm{gm}$ were brought from yankee hatch /Erbil to fish laboratory /agriculture college in Mosul university, fish keep in aquarium $40 * 60 * 40 \mathrm{~cm}$ with aerated contentious drainage water and temperature $18-20^{\circ} \mathrm{C}$. Fish are divided in to the first group have thirty fish were pithing and organs liver, kidney and intestine were collocated (17) and divided in to two subgroups: first sub group was preserved in broth for bacterial isolation until reach to the lab. other parts of internal organs were taken and kept in brain heart infusion broth (18) then incubated at $37^{\circ} \mathrm{C}$ for $24 \mathrm{hr}$ (2). All broths were cultured on blood agar, MacConkey agar, EMB agar and Mannitol Salt Agar. The isolates were grown on agar plates for morphological, biochemical tests and VITEK ${ }^{\circledR} 2$ compact for final identification of isolated bacteria $(19,20)$. Whilst second sub group was fixed in $10 \%$ formalin for histological examination. The samples were dehydrated by ascending ethanol and clearance with xylene, then harding with paraffin $50^{\circ} \mathrm{C}$ and scation with 5micron and staining with hematoxylin and eosin for histological examination (21). Second group included one hundred twenty fish were feeding on commercial pellet and divided randomly to four sub group one of them is consider control group were fish feeding only commercial pellet (Table 1) while the other three groups fish were feeding with commercial pellets with rode powder of Cinnamomum cassia at percentage 0.75, 1 and $1.5 \%$ for 8 weeks (22) after that organs liver, kidney and intestine were collected for histopathological examination.

Table 1: Dietary ingredients and chemical composition (\% DM) of the experimental diets. containing different percentages of Cinnamon powder

\begin{tabular}{|c|c|c|c|c|c|}
\hline Ingredients & Control & & Cinnamon $0.75 \%$ & Cinnamon $1.0 \%$ & Cinnamon $1.5 \%$ \\
\hline Cinnamon powder & - & & 0.75 & 1 & 1.5 \\
\hline Animal protein & 10 & & 10 & 10 & 10 \\
\hline Soybean meal & 30 & & 30 & 30 & 30 \\
\hline Local barley & 20 & & 20 & 20 & 20 \\
\hline Yellow corn & 18.5 & & 18.5 & 18.5 & 18.5 \\
\hline Wheat bran & 19 & & 19 & 19 & 19 \\
\hline Food salt & 1 & & 1 & 1 & 1 \\
\hline Vita. \& Miner. Mix. & 0.5 & & 0.5 & 0.5 & 0.5 \\
\hline Lime stone & 0.5 & & 0.5 & 0.5 & 0.5 \\
\hline Binder (Pentonite) & 0.5 & & 0.5 & 0.5 & 0.5 \\
\hline \multicolumn{6}{|l|}{ Chemical composition } \\
\hline Crude protein & Ether extract & Ash & Crude fiber & Nitrogen free extract & $\mathrm{ME}(\mathrm{MJ} / \mathrm{Kg})$ \\
\hline 25.45 & 3.54 & 6.97 & 4.75 & 52.2 & 13.17 \\
\hline
\end{tabular}

*Calculated according to (23) equation: ME (MJ/Kg) = Protein X 18,8 + Fat X 33,5 + NFE X13,8 (11).

\section{Results}

The results of culture showed isolation of 4 types of pathogenic bacteria from infected fishes that included 24 bacterial isolates which high percentage from both $S$. aureus and E. coli, followed by A. hydrophila, and finally K. pneumonia as in (Table 2).

Histopathological examination of the liver, kidney and intestine organs in the fish infected with the bacterial Aeromonas and Staphylococcus reveals sever pathological lesions characterized by fibrosis, multifocal infiltration of inflammatory cells with hemorrhage and vacuolar degeneration in hepatocyte (Figure 1), while microscopic analysis of kidney reveals coagulative necrosis, interstitial nephritis with hemorrhage (Figure 2), there was also sever enteritis in an infected fish with Staphylococcus characterized by necrosis of the muscular layer with adhesion of the villi and loss the crypt with necrosis (Figure $3)$.
Histological analysis of the organs of a diseased fish treated with various concentration of $C$. cassia $0.75,1$ and $1.5 \%$ indicates various healing stages in the liver, kidney and intestine organs. Microscopic examination of liver of fish in group treated with $0.5 \%$ of the $C$. cassia exhibit vacuolar degeneration, infiltration of inflammatory cells with hemorrhage and fibrosis and edema (Figure 4) whereas vacuolar degeneration and dilatation of the sinusoid investigated in the liver of fish in that group treated with $C$. cassia at $1 \%$ (Figure 5), while in comparison to the microscopical examination of the liver in the fish was treated with $1.5 \%$, the liver appear normal there was only moderate infiltration of inflammatory cells (Figure 6).

While microscopic examination of kidney in fish treated with 0.75 and $1 \%$ of $C$. cassia exhibit coagulative necrosis in renal tubules with sever interstitial nephritis with hemorrhage with detection bacterial colonies (Figure 7), in group $1.5 \%$ the lesions is less severity and the section appear normal except there was moderate interstitial nephritis (Figure 8). 
Iraqi Journal of Veterinary Sciences, Vol. 35, No. 4, 2021 (733-738)

Table 2: Biochemical characteristics of the G-ve and S. aureus isolates using VITEK® 2 Compact

\begin{tabular}{|c|c|c|c|c|c|c|c|}
\hline \multicolumn{5}{|c|}{ Gram-negative isolates } & \multicolumn{3}{|c|}{ S. aureus isolate } \\
\hline Code & Reagent & E.coli & Result & Biochemical test & N. & Biochemical test & Result \\
\hline 9 & BGAL & - & + & ADH1 & 8 & ADH1 & + \\
\hline 11 & BNAG & - & - & BGAL & 9 & BGAL & - \\
\hline 17 & BGUL & - & + & AGLU & 11 & AGLU & + \\
\hline 18 & Dmal & + & + & PHOS & 19 & PHOS & + \\
\hline 23 & Proa & - & - & PROA & 23 & PROA & - \\
\hline 33 & SAC & - & - & Bgur & 27 & Bgur & - \\
\hline 36 & CIT & + & + & ILTAK & 39 & ILTAK & + \\
\hline 43 & NAGA & - & - & LAC & 42 & LAC & - \\
\hline 45 & PHOS & - & + & Dmal & 45 & Dmal & + \\
\hline 48 & LDC & + & + & NC6.5 & 50 & NC6.5 & + \\
\hline 57 & BGUR & + & - & SAL & 59 & SAL & - \\
\hline 64 & Ilata & - & + & Dtre & 62 & Dtre & + \\
\hline
\end{tabular}

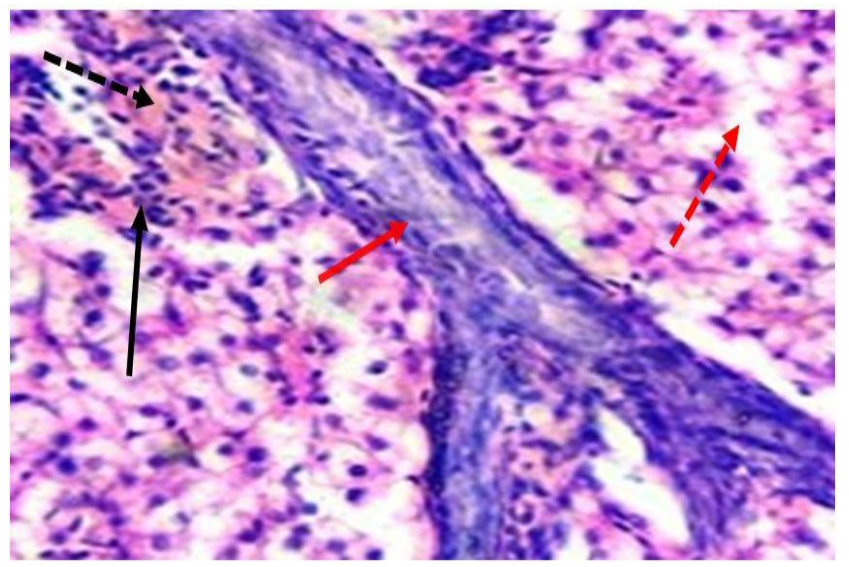

Figure 1: Microscopic examination of liver in infected fish C. carpio reveals fibrosis (red row), vacuolar degeneration (red dot row), infiltration of inflammatory cells (black dot row) with hemorrhage (black dot row), H\&E $1 * 40$.

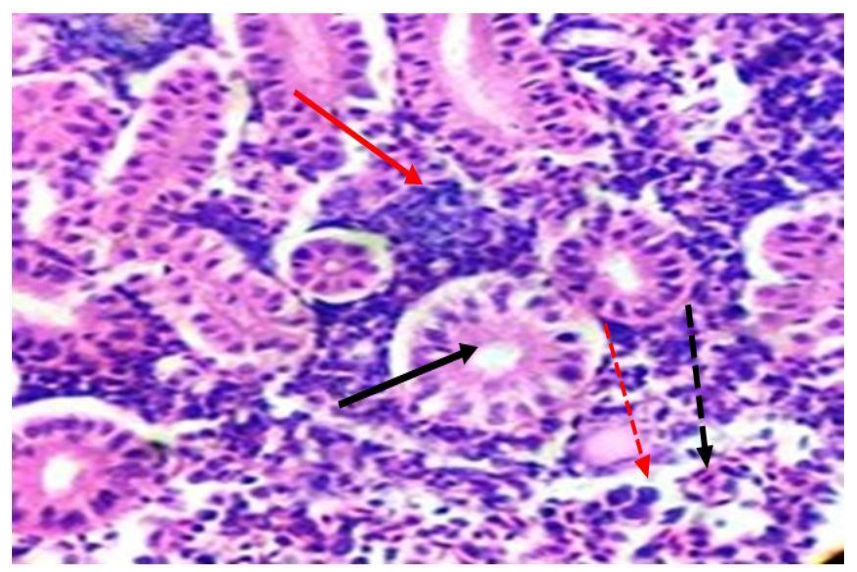

Figure 2: Microscopic examination of kidney in infected fish C. carpio reveals caogualative necrosis (black row), interstitial nephritis (red row) with hemorrhage (black dot row) with edema (red dot row), H\&E $1.7 * 40$.

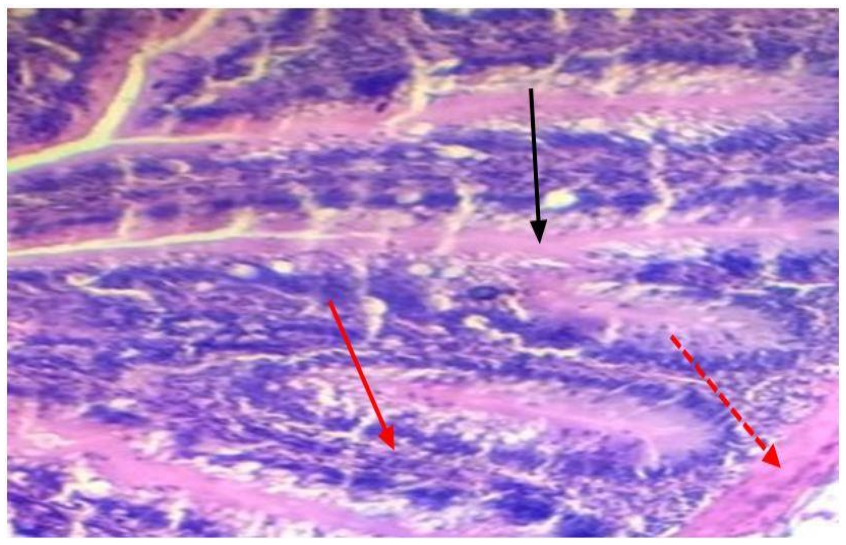

Figure 3: Microscopic examination of intestine in infected fish C. carpio reveals necrosis of muscular layer (red dot row), with adhesion of villi (red row) and loss the crypt with necrosis (black row) H\&E 2.9*10.

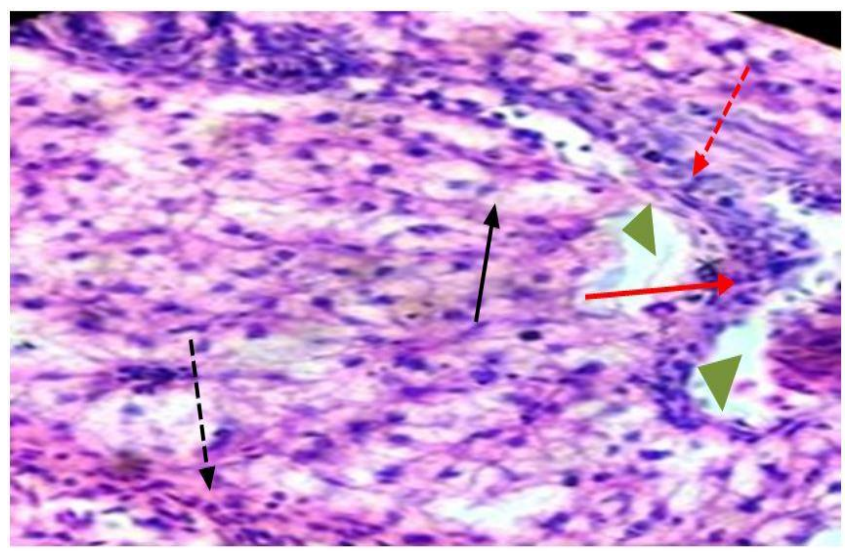

Figure 4: Microscopic examination of liver in infected fish C. carpio treated with $0.75 \%$ of C. cassia vacuolar degeneration (black row), infiltration of inflammatory cells (red row) with hemorrhage (black dot row) and fibrosis (red dot row) and edema (head row) H\&E, $1 * 10$. 


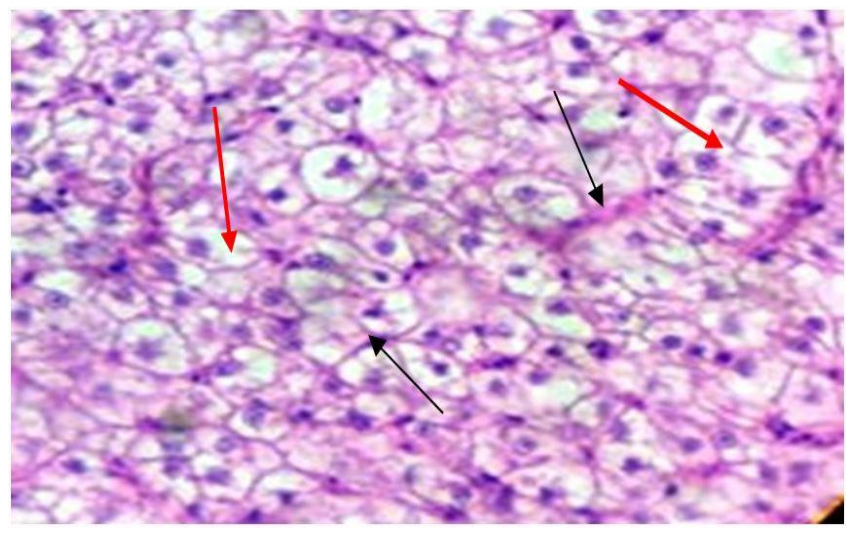

Figure 5: Microscopic examination of liver in infected fish C. carpio treated with $1 \%$ of C. cassia vacuolar degeneration (red row) and dilatation of sinusoid (black row) $\mathrm{H} \& \mathrm{E}, 1 * 40$.

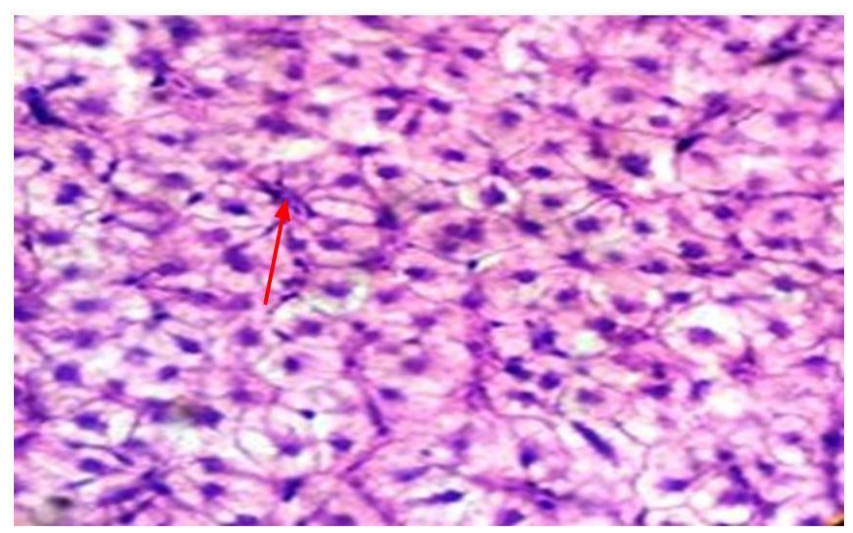

Figure 6: Microscopic examination of liver in infected fish C. carpio treated with $1.5 \%$ of C. cassia moderate infiltration of inflammatory cells (red row) H\&E, $1 * 40$.

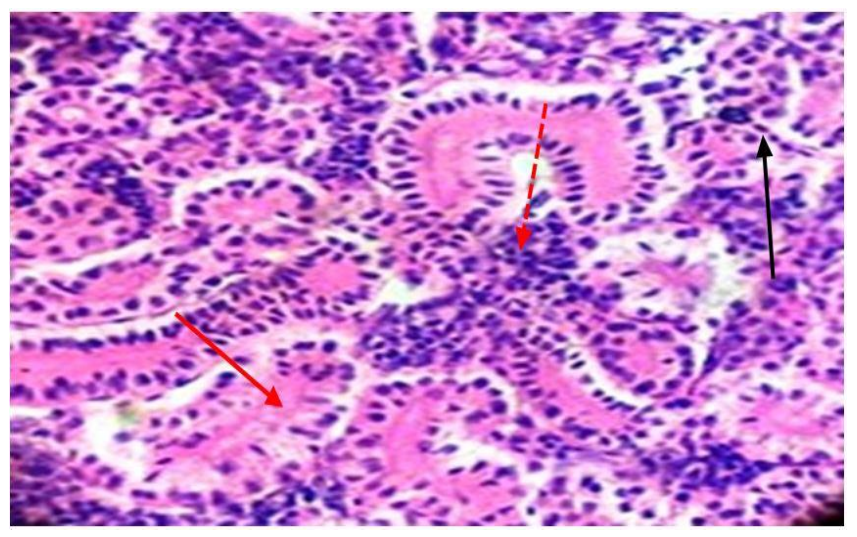

Figure 7: Microscopic examination of kidney in infected fish $C$. carpio treated with $1 \%$ of $C$. cassia coagulative necrosis in renal tubules (red row) sever interstitial nephritis with hemorrhage (red dot row), present colonies of bacteria (black row) H\&E, $1 * 40$.

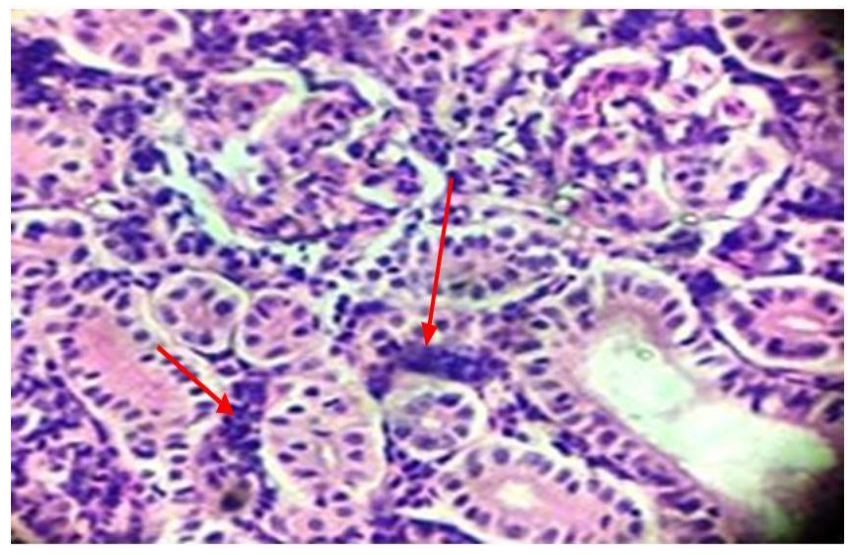

Figure 8: Microscopic examination of kidney in infected fish $C$. carpio treated with $1.5 \%$ of $C$. cassia exhibit moderate interstitial nephritis (red row) H\&E, $1 * 40$.

There were no effects of $C$. cassia at $0.75 \%$ in repairing and healing the damage in illness fish intestine the microscopic examination reveals sever enteritis, hyperplasia of epithelial cells, adhesion of villi and loss crypt with necrosis at the apex of villi (Figure 9).

Lesions were less severity in group treated with $1 \%$ of C. cassia there was only moderate enteritis and less adhesion between villi with vacuolar degeneration in lamina properia (Figure 10).

more common effect of $C$. cassia at group treated with $1.5 \%$ the lesions less in severity the microscopic examination exhibit normal structure except there was slight infiltration of inflammatory cells with vacuolar degeneration see (Figure 11).

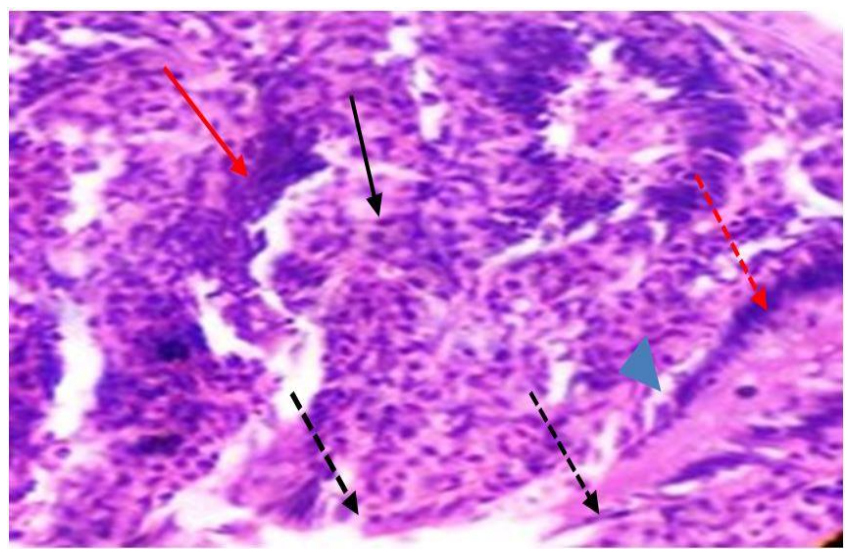

Figure 9: Microscopic examination of intestine in infected fish $C$. carpio treated with $0.75 \%$ of $C$. cassia exhibit sever infiltration of inflammatory cells (red row), hyperplasia of epithelial cells (red dot row), adhesion of villi (black row) and loss crypt (head row) with necrosis at the apex of villi (black dot row) H\&E, 1* 10. 


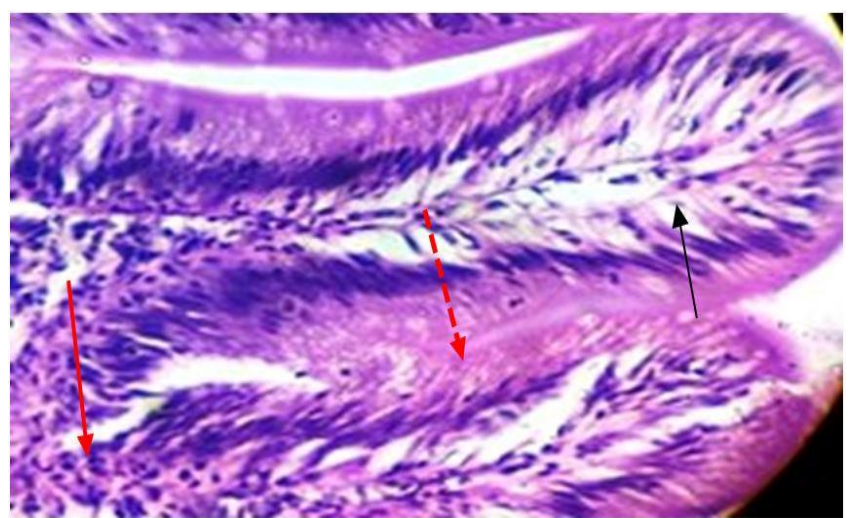

Figure 10: Microscopic examination of intestine in infected fish $C$. carpio treated with $1 \%$ of $C$. cassia moderate infiltration of inflammatory cells (red row) and less adhesion between villi (red dot row) with vacuolar degeneration in lamina properia (Black row) H\&E, $1 * 40$.

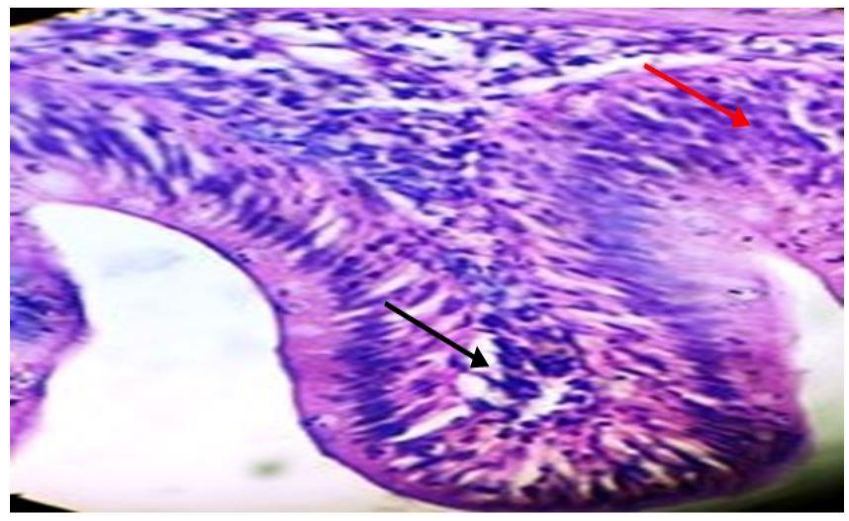

Figure 11: Microscopic examination of intestine in infected fish $C$. carpio treated with $1 \%$ of $C$. cassia slight infiltration of inflammatory cells (red row) with vacuolar degeneration (black row) $\mathrm{H} \& \mathrm{E}, 1 * 40$.

\section{Discussion}

Results in current study showed high percentage from both $S$. aureus and E. coli, followed A. hydrophila, and finally $K$. pneumonia, these results correspond to the results of zimbabwe study that shows that $E$. coli was the most isolate followed by $S$. aureus (23-25). Medicinal plants have properties as antiviral, antibacterial and anti-parasite (26), so they can be alternative the antibiotics to prevent infectious disease and also have been used for growth promoters and prevent stress, one of them was C. cassia which have properties of antioxidant and antibacterial $(27,28)$. Histological changes consider as a good indicator for fish health status, so the result of present study shows that when illness fish treated with extracted rods $C$. cassia at $0.75,1$ and $1.5 \%$ for 8 weeks reveals the percentage $1.5 \%$ is more effective in repair and regenerative tissue damage in liver, kidney and intestine through it is important roles as antibacterial against Staphylococcus and Aeromonas, these result agreement with $(29,30)$, also agreement with previous study of (31) who refer to it is effect of $C$. cassia as hepatoprotective and gastroprotective effects (15). C. cassia stimulate innate immunity as white blood cells which kill bacteria or by reactive oxygen and nitrogenous species which are toxic to bacteria $(32,33)$, other immune defense mechanism is activation to lysosomal enzyme (34). Cinnamomum spp. is improve tissue is through it is activation to insulin-like growth factor (IGF-1) to increase metabolism and increase growth performance and enhance collagen and protein biosynthesis which increase body weight and maintain immune response and keep fish health (35).

\section{Conclusion}

More common effect of $C$. cassia at group treated with $1.5 \%$ the lesions more less in severity the microscopic examination exhibit normal structure except there was slight infiltration of inflammatory cells with vacuolar degeneration, so $C$. cassia have important role in regenerative tissue damage and keep fish in health status.

\section{Acknowledgment}

Authors thankfully all members of Collage of Veterinary Medicine and College of Agriculture, University of Mosul.

\section{Conflict of interest}

No conflict of interest.

\section{References}

1. Abd-Al-Hammeed MA. The blue revolution (Pisciculture). $2^{\text {nd }}$ ed. Mansora: Agriculture College Press; 2019. 5 p.

2. Quinn PJ, Carter ME, Markey BK, Leonard F, Fitzpatrick ES, Fanning $S$, Hartiggan P. Clinical veterinary microbiology and microbial disease. $2^{\text {nd }}$ ed. Iowa: Black Well Publishing Company;2011. 234-324.

3. Quesada SP, Paschoal JA, Reyes FG. Considerations on the aquaculture development and on the use of veterinary drugs: Special issue for Fluoroquinolones. J Food Sci. 2013;78(9):1321-33. Doi: $10.1111 / 1750-3841.12222$

4. Abdulrahman NM, Hama HJ, Hama ShR, Hassan BR, Nader PJ. Effect of microalgae Spirulina spp. as food additive on some biological and blood parameters of common carp Cyprinus carpio L. Iraqi J Vet Sci.2019;33(1):27-31. Doi: 10.33899/ijvs.2019.5527.1049

5. Magouz FI, Salem MS, Hashad MA. Effect of some Mycotoxin on growth performance and feed utilization in Nile tilapia(Oreochromis niloticus). Iraqi J Vet Sci. 2019;32(1):99-108. Doi: 10.33899/ijvs.830

6. Ranasinghe P, Jayawardana R, Galappaththy P, Constantine G, De Vas Gunawardana N, Katulanda P. Efficacy and safety of 'True'cinnamon (Cinnamomum zeylanicum) as a pharmaceutical agent in diabetes: a systematic review and meta-analysis. Diabetic Med. 2012;29(12):1480-1492. Doi: 10.1111/64-5491.2012.03718.X

7. Khasnavis S, Pahan K. Sodium Benzoate, a metabolite of cinnamon and a food additive, upregulates neuroprotective Parkinson disease 
protein DJ-1 in astrocytes and neurons. J Neuroimmune Pharmacol. 2012;7:424-435. Doi: 10.1007/S11481-011-9286-3

8. Ngugi, CC, Oyoo-Okoth E, Mugo-Bundi J, Orina PS, Chemoiwa E, Aloo PA. Effects of dietary administration of stinging nettle (Urtica dioica) on the growth performance, biochemical, hematological and immunological parameters in juvenile and adult Victoria labeo (Labeo Victorianus) challenged with Aeromonas hydrophila. Fish Shellfish Immunol. 2015;44(2) :533-541. Doi: 10.1016/J.Fsi.2015.03.025

9. Stratev D, Zhelyazkov G, Noundou XS, Krause RWM. Beneficial effects of medicinalp in fish diseases. Aquac Int. 2018;26:289-308. Doi: 10.33448/Rsd-V9i4.3014

10. Reverter M, Bontemps N, Lecchini D, Banaigs B, Sasal P. Use of plant extracts in fish aquaculture as an alternative to chemotherapy: current status and future perspectives. Aquacul. 2014;433:50-61 Doi: 10.1016/J.Aquaculture.2014.05.048

11. Hai NV. The use of medicinal plants as immunostimulants in aquaculture: A review. Aquacul. 2015;446:88-96. Doi: 10.1016/j.aquaculture.2015.03.014

12. , Högberg LD, Heddini A, Cars O. The global need for effective antibiotics: challenges and recent advances. Trends Pharmacol Sci. 2010;31:509-15. Doi: 10.1016/J.Tips.2010.08.002

13. Brierley SM, Kelber O. Use of natural products in gastrointestinal therapies. Curr Opin Pharmacol.2011;11:604-611. Doi: 10.10.09.007

14. Al-Zubaidy KI. Cinnamon's antibacterial activity on the bacterial isolates from urinary tract infections. World $\mathrm{J}$ Pharmaceut Res. 2017;6(17):81-91. Doi: 10.20959/wjpr201717-10304

15. Sabitha K, Venugopal B, Rafi M, Rammana KV. Role of antioxidant enzymes in glucose and lipid metabolism in association with obisty and 2 diabetes. Am J Med Sci Med. 2014;2(1):21-24. Doi: 10.12691/Ajmsm-2-1-5

16. Mayyahi M, Al-Jumaa Z, Al-Taee S, Nahi HH, Al-Hamdany MO, AlSalih MA, Al-Mayahi B. Bioaccumulation of heavy metals and histopathological changes in muscles of common carp Cyprinus carpio L. in the Iraqi rivers. Iraqi J Vet Sci.2020;Xxxxxx,Xxxxxxxx Doi: 10.33899/ijvs.2020.126748.1368

17. Lucky Z.Methods for the diagnosis of fish diseases.New Delhi: Amerind Publishing; 1977. $40 \mathrm{p}$

18. Meenashi V, Narayanan KR, Venkatraman, R. Evaluation of intestinal microbial population and their physiological grouping of wild common carp (cyprinus carpio L.) exposed to seasonal variations. J Bio Sci Res. 2010;1(3):158-162. Doi: 10.3389/Fendo.2010.00009

19. Mulyani Y, Aryantha IN, Suhandono S, Pancoro A. Intestinal bacteria of common carp (Cyrinus carpio L.) as biological control agent for Aeromonas. J Pure Appl Microbiol. 2018;12(2):601-610. Doi: 10.22207/JPAM.12.2.18

20. Al-Harbi AH, Uddin MN. Aerobic Bacterial flora of Common Carp (Cyprinus carpio L.) cultured in earthen ponds in Saudia Arabia. J Appl Aquaculture.2008;20(2):108-119. Doi: 10.1080/30802197292

21. Luna LG. Manual of histological staining methods of armed forces institute of pathology. $3^{\text {rd. New }}$ York: McGraw-Hill Book Company;1968. 12-14p.

22. Mohammad MA. Effect of adding different levels of cinnamon (Cinnamomum sp) on growth and chemical composition criteria of common carp Cyprinus carpio L. Iraqi J Vet Sci. 2020;xx, No. x, 20xx (xx-xx). Doi: 10.33899/ijvs.2020.126362.1308

23. Smith RG. A method for measuring digestibility and metabolizable of energy of feeds. Prog Fish. 1971;33:132-134. Doi: 10.1577/1548-O;2

24. Manhondo P, Gono RK, Muzondiwa J, Mafa B. Isolation and identification of pathogenic bacteria in edible fish: A case study of bacterial resistance to antibiotics at lake Chivero, Zimbabwe. Afr J Agr Res. 2018;2(9)1-5. Doi: 10.1091301/10.1080

25. Musthafa MS, Ali ARJ, Ali ARH. Effect of Shilajit enriched diet on immunity, antioxidants, and disease resistance in Macrobrachium rosenbergii (De Man) against Aeromonas hydrophila. Fish Shellfish Immunol. 2016;57: 293-300. Doi: 10.1016/i.fsi.2016.08.033

26. Ahilan B, Nithiyapriyatharshini A, Ravaneshwaran K. Influence of certain herbal additives on the growth, survival and disease resistance of goldfish, Carassius auratus (Linnaeus). Tamilnadu J Vet Ani Sci.2010;6(1):5-11. [available here]
27. Plaisier C, Cok A, Scott J, Opejin A, Bushhouse KT, Sallie M, Louters LL. Effects of cinnamaldehyde on the glucose transport activity of GLUT1. Biochimie.2011;93:339-44. Doi: 10.1016/J.Biochi.2011.10.006

28. Ranasinghe P, Pigera S, Premakumara GA, Galappaththy P, Constantine GR, Katulanda P. Medicinal properties of 'True' cinnamon (Cinnamomum zeylanicum): A systematic Review. BMC Complement Altern Med. 2013;13:275. Doi: 10.472-6882-13-275

29. Zarchil MA, Babaei A. An investigation of thyme effect on Helicobacter pylori. Middle East J Sci Res.2006;1:54-57. Doi: 10.1016/S2468-1253(17)30219-4

30. Al-Saghir M. Antibacterial assay of Cinnamomum cassia (Nees and Th. Nees) Nees ex Blum Bark and Thymus vulgaris L. leaf extracts against five pathogens. J Biol Sci. 2009;9(3):280-282. Doi: 10.3923/jbs.2009.280.282

31. Herman A, Herman A, Domagalska B, Młynarczyk A. Essential oils and herbal extracts as antimicrobial agents in cosmetic emulsion. Indian J Microbiol. 2013;53:232-237. Doi: 10.1007/0329-0

32. Alexander C P, Kirubakaran CJW, Michael RD. Water soluble fraction of Tinospora cordifolia leaves enhanced the non-specific immune mechanisms and disease resistance in Oreochromis Mossambicus. Fish Shellfish Immunol. 2010;29:765-72. Doi: 10.1016/J.Fsi.2010.07.003

33. Harikrishnan R, Kim MC, Balasundaram C, Heo MS. Hericium erinaceum enriched diets enhance the immuneresponse in Paralichthys olivaceus and protect from Philasterides dicentrarchi infection. Aquacul. 2011;318:48-53. Doi: 10.1016/lture.2011.04.048

34. Engstad RE, Robertsen B, Frivold E. Yeast glucan induces increase in lysozyme and complement-mediated hemolytic activity in atlantic salmon blood. Fish Shellfish Immunol. 1992;2: 287-297. Doi: 10.1006/Fsim.2000.0291

35. Vinasyiam A, Suprayudi S, Alimuddin A. Digestive enzymes actyvities in Oreochromis niloticus fed diet supplemented with recombinant growht hormone. J Akuakultur Indonesia. 2016;15(1):1523. Doi: $10.19027 /$ Jai.15.15.23

\section{تأثير إضافة القرفة على معالجة الإصابات المرضية لإصبعيات اسماك الكارب الثنائع}

محمود احمد محمد' ، شهباء خليل الطائيَ وزهر اء مصطفى الجمعةr

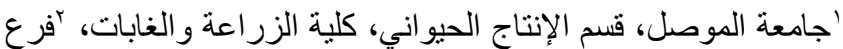

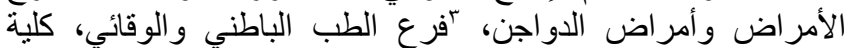
الطب البيطري، جامعة الموصل، الموصل، العن، العراق الطر البرن

الخلاصة

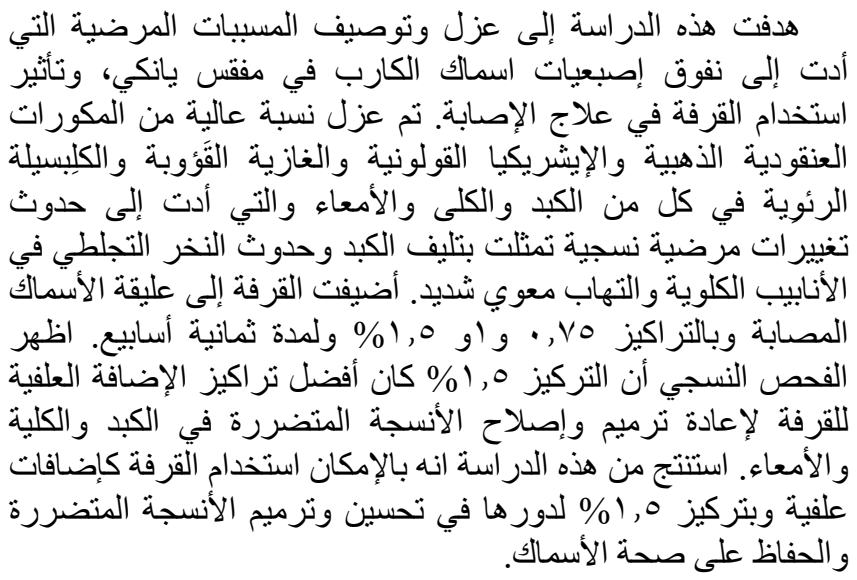

